\title{
Parameterized water layer reconstruction for first arrivals in OBN data
}

Lucas Fragoso Vale Paiva ${ }^{1}$, Francisco Carlos Lajús Jr. ${ }^{1}$, André Bulcão ${ }^{2}$, Bruno Dias ${ }^{2}$ Antonio Henrique da Fontoura Klein ${ }^{1}$

${ }^{1}$ Universidade Federal de Santa Catarina - UFSC

${ }^{2}$ Petróleo Brasileiro S.A. - PETROBRAS

Copyright 2021, SBGf - Sociedade Brasileira de Geofísica.

This paper was prepared for presentation at the $17^{\text {th }}$ International Congress of the Brazilian Geophysical Society, held in Rio de Janeiro, Brazil, 8 November to 11 November, 2021.

Contents of this paper are to be reviewed by the Technical Committee of the $17^{\text {th }}$ International Congress of The Brazilian Geophysical Society and do not necessarily represent any position of the SBGf, its officers or members. Electronic reproduction or storage of any part of this paper for commercial purposes without the written consent of The Brazilian Geophysical Society is prohibited.

\section{Abstract}

In this work we present current results for an ongoing formulation of an inversion method focused on water velocity reconstruction of Ocean Bottom Nodes (OBN) data, based strictly on the varying behavior of first arrivals with the source offset distance. Given the similarities with the field of Oceanic Acoustic Tomography (OAT), some typical assumptions applied to the acoustic propagation on the ocean environment, such as the linearized disturbances of the sound velocity, are here enforced. Additionally, two sets of available oceanographic information, that can be known a priori for a certain region of interest, are considered: 1) monthly-averaged sound velocity profiles from reanalysis models, and 2) a parameterized set of modes to describe velocity disturbances. Our results are verified to provide improved water velocity reconstructions over a verticallyhomogeneous profile, which is typically considered in geophysical imaging.

\section{Introduction}

In recent decades, a range of marine seismic methods have been consolidated for the visualization of subsurface geological structures located beneath the ocean environment (SHERIFF, 2002). Among the different types of acquisition, the use of ocean bottom receivers, such as the Ocean Bottom Nodes (OBNs), constitutes a recurring choice of survey method in modern exploration and reservoir monitoring (DONDURUR, 2018). The reason for this is mainly due the numerous advantages over more conventional proposals (with towed streamers), such as the improved data quality, higher repeatability and provision of full-azimuth coverage, thus standing as a remarkably interesting method in 3D/4D seismic surveys (CYPRIANO, 2019).

Usually in marine seismic surveys, the ocean is taken as a homogeneous layer, characterized by some averaged (in time and/or space) constant velocity value (ZOU et al., 2018). Specially for 3D and 4D acquisitions, whereas acquisition periods reach weeks up to months, meso and submeso-scale oceanic processes (eddies, currents, tides, among others) are already known to affect quality of the acquired seismic data (WOMBELL, 1996; BERTRAND and MACBETH, 2003; LACOMBE et al., 2006). The search for more accurate water velocity corrections thus requires a detailed description of such water sound velocity variations, that are related to the varying ocean dynamics affecting mostly water temperature and salinity (JENSEN et al., 2011; ETTER, 2018). Particularly in the case of horizontally distributed $\mathrm{OBN}$ geometry, the restriction to consider only information of first arrivals in a known vertically stratified media can be further complicated as discussed in a companion paper (LAJÚS and KLEIN, 2021). Improvements were suggested by additional seismic data, such as multiple reflections trapped on the water column (BOEHM et al., 1995; GRAD et al., 2011) or simultaneous measurements taken by vertical streamers (ZOU et al., 2018). However, here we pursue this direction with freely available information of the ocean media.

Thus, in the present work we investigate the application of a possible inversion formulation focused on detailed water velocity reconstruction, that is constrained to use only first arrival traveltimes from OBN data. The idea is based on some underlying principles typically adopted in the field of Ocean Acoustic Tomography (OAT), but now applied to horizontally distributed arrays. Our study has mostly an exploratory character, towards improved water velocity corrections.

\section{Ocean Data}

Reanalysis products taken from GLORYS (Global Ocean Reanalysis and Simulations) can be used to obtain some notion of temporal-spatial variation of sound velocity profiles occurring in a certain region of interest. From this, monthly-averaged veritical (1D) sound velocity profiles are readily obtained, here exemplified in Figure 1, accounting a 4 months period of OBN seismic survey.

Assuming these monthly-averaged 1D sound velocity profiles as reference base-states $c_{0}(z)$, a certain true velocity profile $c(\vec{x})$ can be recovered with the inclusion of some velocities disturbances $\delta c(\vec{x})$, in the form of (MUNK and WUNSCH, 1979)

$$
c(\vec{x})=c_{0}(z)+\delta c(\vec{x}) .
$$

For locally-dependent vertical velocity disturbances, $\delta c(z)$ can be decomposed by a sum of weighted modal contributions,

$$
c(z)=c_{0}(z)+\sum_{k}^{i} a_{k} B_{k}(z),
$$

where $B_{k}(z)$ stands for the k-th mode, and $a_{k}$ their associated coefficients. Here we are interested in some 


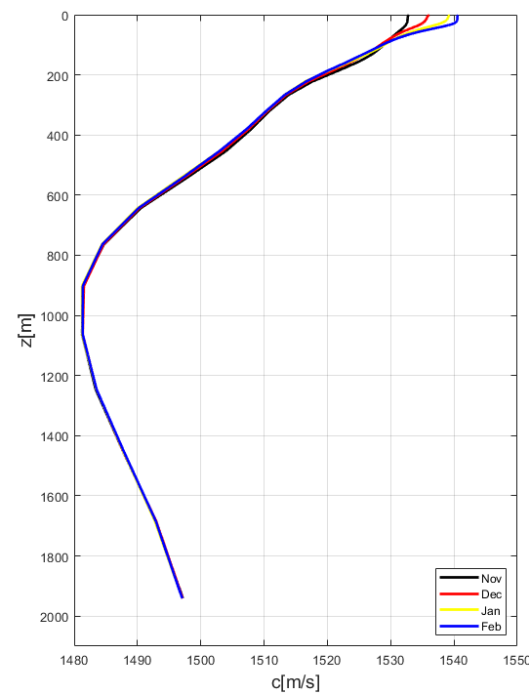

Figure 1: Time-average sound velocity profiles for November (black), December (red), January (yellow) and February (blue), in a period between 1993 and 2018, from GLORYS reanalysis model.

alternative choice of modal representation, compared to the usual application of Empirical Orthogonal Functions (EOF), which is extracted from large historical series data (CORNUELLE et al., 1985). Our interest is based mostly on the possibility to account low-energy (in planetary scale) short-time spatial representation of the disturbances, focusing more control over the mode shape, similarly to the application of radial basis functions (BUHMANN, 2003) or B-splines (COX and VERSCHUUR, 2001).

In order to built such spatial mode alternative of the aforementioned disturbances, we consider 23 sound velocity measurements that were obtained during a seismic acquisition between November 2017 and February 2018, shown in Figure 2. Among these velocity profiles, 9 were collected in November, 4 in December, 7 in January and 3 in February. During this period, one measured profile (socalled P12 - red line) is verified with a more pronounced variation in the sound velocity and temperature along the upper region (first $700 \mathrm{~m}$ ), in comparison with the others. Analysis of satellite altimeter data suggests an association with cold cyclonic eddies (BELO, 2011).

By evaluating the behavior of the 23 disturbances (subtracting the profiles by their monthly-averaged associated ones), it is found that some appropriate choice for the basis functions could assume the form of Fourier series with exponential decay along depth, such as

$$
\delta c(z)=a_{0}+\sum_{k=1}^{4}\left[a_{k} \cos \left(2 \pi k \frac{z}{R}\right)+b_{k} \sin \left(2 \pi k \frac{z}{R}\right)\right] e^{g(z)}
$$

Here, $a_{0}, a_{k}$ and $b_{k}$ are defined as the expansion coefficients, $z$ is the depth in meters, and $g(z)=h z / D$ where $D$ is defined as the maximum depth of the velocity profiles (here, $D=2088 \mathrm{~m}$ ). The terms $\mathrm{R}$ and $\mathrm{h}$ are free constants, that require additional estimation to sustain the linear dependence. In Figure 3, results for the curve fitting
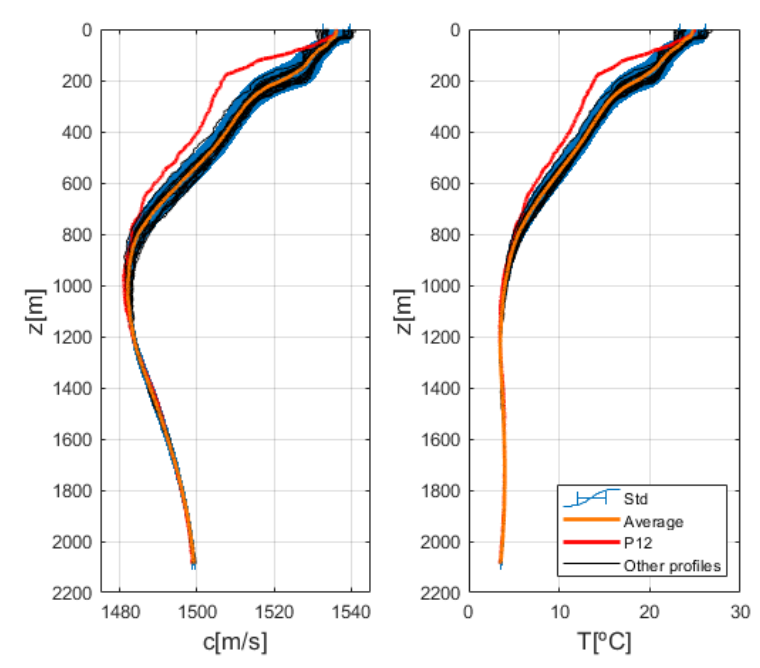

Figure 2: Sound speed (left) and temperature (right) profiles, indicated by the overlap of the 23 profiles (black lines) the mean (orange line), standard deviation (blue area), and P12 off-trend (red lines).

of such parametrization are exemplified, displaying also their residuals. In general, low deviations are verified for all 23 profiles, with a maximum residual value of $3.14 \mathrm{~ms}^{-1}$, obtained in P14, suggesting a good characterization of the expected variations. Largest deviations are in generall observed in the shallowest ocean region $(z \approx 200 \mathrm{~m})$.
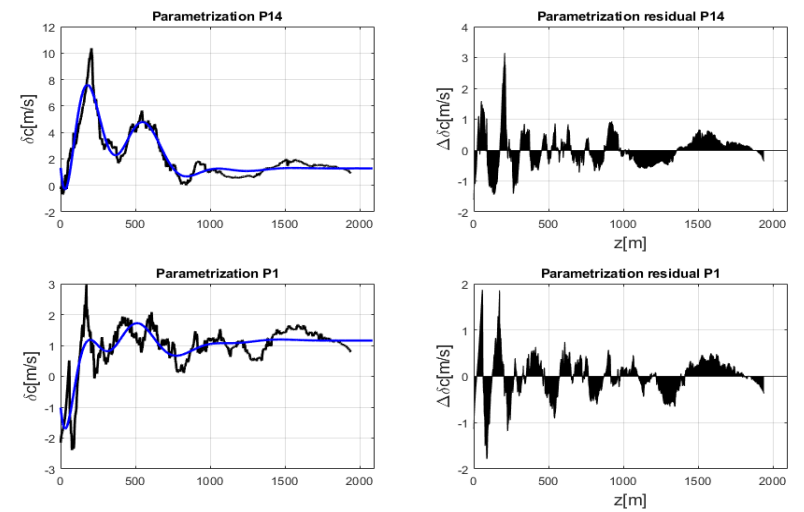

Figure 3: Parameterization of P1 (down-left) and P14 (topleft). Comparison between the real curve (black line) and the parameterized curve (blue line). Residual obtained for each depth (right).

In Figure 4 the cumulative distribution of the values of the Adjusted Coefficient of Determination (a metric to evaluate the fit quality) is presented, considering different values of $\mathrm{R}$ and $\mathrm{h}$ for the 23 profiles. The best results are obtained with $R=1800$ and $h=-10$, where $80 \%$ of the values remain above 0.67 , and $50 \%$ are above 0.86 . Nonetheless, small differences are generally observed on the fitted velocity profiles with the varying $R$ and $h$ parameters, thus showing certain robustness regarding this choice of basis functions. 

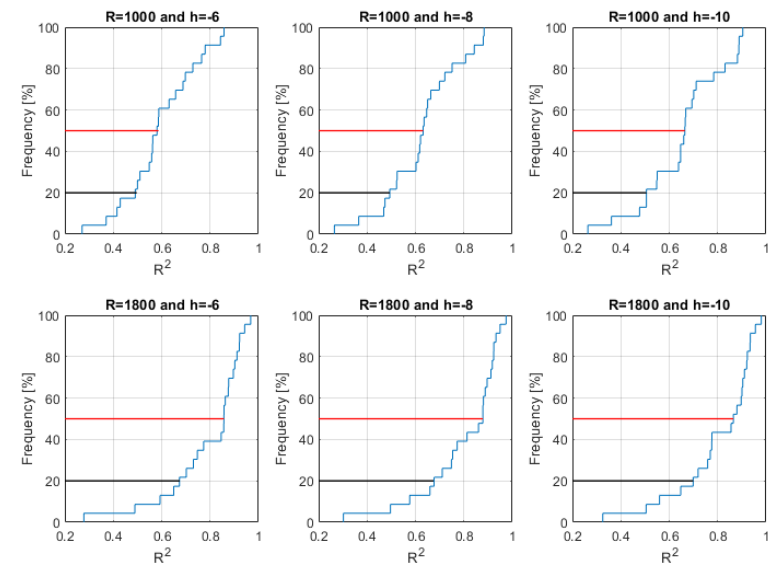

Figure 4: Cumulative distribution of the results of the parameterization Adjusted Coefficients of Determination considering other values of the $\mathrm{R}$ and $\mathrm{h}$ parameters. The red (black) line shows the distribution of $50 \%(80 \%)$ of the results of the profiles.

\section{Direct Problem}

In essence, traveltime tomography is based on the idea that the the total time $t$ associated with a given ray (from source to receiver) can be defined by the integral of the slowness, $1 / c(z)$, along the ray path. For a linearized assumption regarding the velocity disturbances (typically considered in OAT), such traveltime perturbations $\delta t$ end up related to velocity perturbations $\delta c$, as

$$
\delta t_{i}=t_{i}-\int_{s_{i}} \frac{1}{c_{0}(z)} \vec{d} s \approx-\int_{s_{i}} \frac{\delta c(z)}{c_{0}(z)^{2}} \vec{d} s,
$$

where $t_{i}$ is the ray tracing travel time of the $\mathrm{i}$-th ray recorded at the i-th receiver, $S_{i}$ the arc length along the ray path and $c_{0}(z)$ a reference base profile (MUNK and $\mathrm{WUNSCH}$, 1979). By assuming a straight ray approximation, at least in a near offset region BREGMAN et al. (1989); BERTRAND and MACBETH (2003), for a simpler model description for the propagation problem, eq. (4) is rewritten as

$$
\delta t_{i}=t_{i}-t_{0 i}=-\int_{0}^{1} \frac{\delta c(\tau)}{c_{0}(\tau)^{2}}\left|\tau_{i}^{\prime}\right| d \tau
$$

In this equation $t_{i}$ is associated with acquired travel times that are supposed to be taken from OBN data. In the absence of these quantities, here they are estimated from usual ray-tracing algorithms. Conversely, the reference traveltimes $t_{0 i}$ obtained for the monthly-averaged profiles, are calculated with straight ray approximation, thus evoking a distinct choice in the forward modeling (to avoid an inversion crime). The term $\left|\tau_{i}^{\prime}\right|$ is associated with a proportionality coefficient of $\partial \tau / \partial \vec{x}$, and the sound speed profile, previously a function of $z$, now becomes dependent of the $\tau$ parametric variable.

Deviations between these two forward models are accessed through a comparative analysis between traveltimes results, for the 4 velocity models of the monthly base profiles $c_{0}(z)$, obtained from GLORYS. Figure 5 exemplifies these results, for January. Considering the short offsets, up to $2200 \mathrm{~m}$, absolute differences are found below $10^{-5} s$, while more distant offsets (up to $4000 \mathrm{~m}$ ) display increasing deviations on the order of $10^{-4} \mathrm{~s}$. Nonetheless, these differences of the traveltimes are considerably lower than those (physically) related to the 23 profiles, which are of $10^{-3} s$ order of magnitude for the near-offsets (up to $4500 \mathrm{~m}$ ), and $10^{-2} s$ in the far-offset. This result, therefore, verify the somewhat applicability of the straight ray assumption in determination of traveltimes.
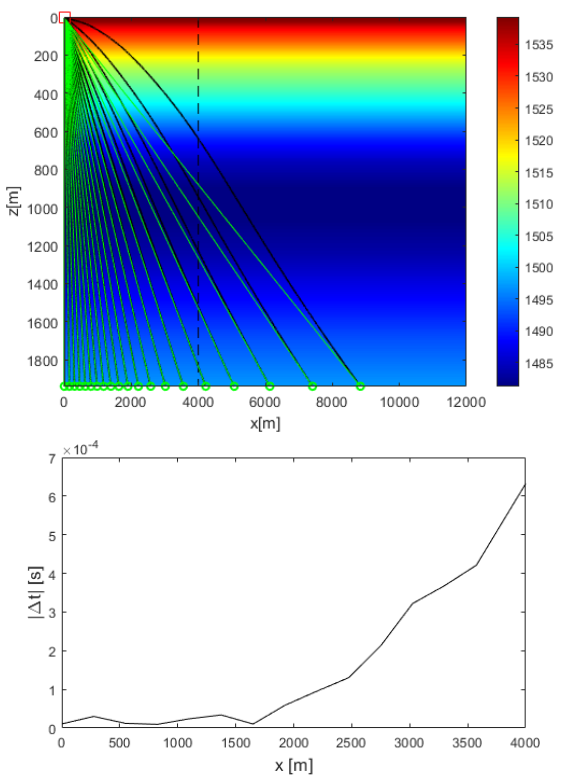

Figure 5: Example of ray propagation paths obtained for the January average profile velocity models (top). Travel times calculated by ray tracing, (black lines) and straight rays (green lines). Absolute deviations of travel times between the two methods (down).

\section{Inversion results}

Considering the linearization of the disturbances, their association with modal solutions and straight ray approximation, the proposed inversion becomes entirely linear, and not necessarily requiring a iterative procedure. The Singular Value Decomposition (SVD) can be readily applied to calculate the pseudo-inverse matrix required for the determination of $a$ coefficients, as

$$
a=V S^{-1} U^{T} \delta t
$$

where $U$ and $V$ are the left and right eigenvectors, and $S$ is a diagonal rectangular matrix, having the singular values. Once the coefficients $a_{0}, a_{k}$ and $b_{k}$ are obtained, their contribution can be added to the base-state, in order to recover the real water velocity. Results obtained by all 23 velocity profiles are presented in Figure 6, where the same reconstruction process for homogeneous base-state profile $\left(c_{0}(z)=1500 \mathrm{~ms}^{-1}\right)$ is also shown. The proposed inversion is found to promote improved results for the velocity model, when compared to spatially-homogeneous velocity models. The ambiguities associated to the null-space, however, deserves further attention for the continued development of this proposal. 

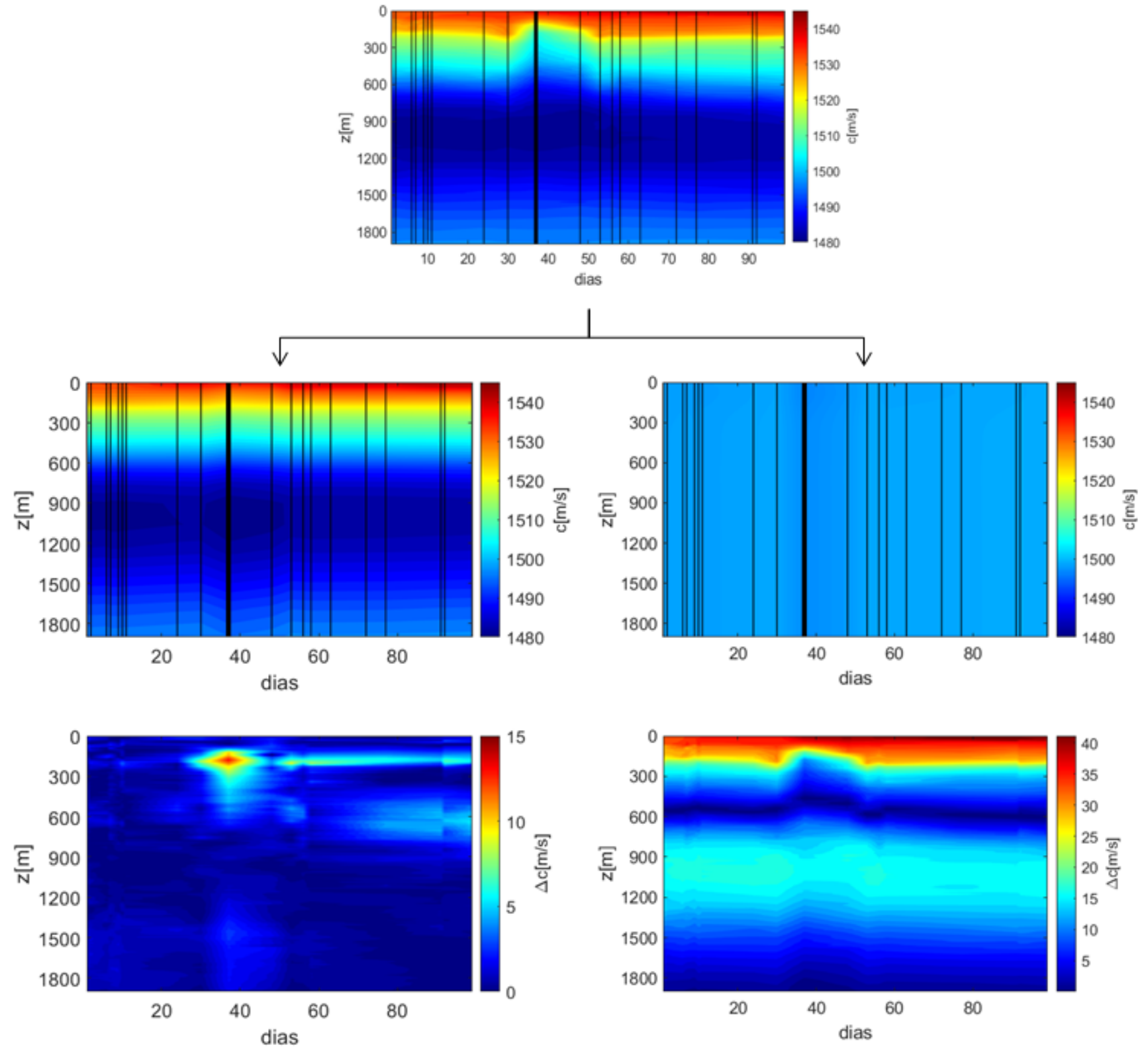

Figure 6: Comparisons between true water velocity profiles (top), and those reconstructed from the proposed scheme (left) and with vertically-averaged velocity profiles(right). RMSE values are presented (down), showing maximum deviations from the true velocity model. The vertical lines indicate the time distribution of the acquired 1D velocity profiles. The pronounced black line is related to $\mathrm{P} 12$, where maximum deviations are obtained (RMSE $=13.31 \mathrm{~ms}^{-1}$, at $\mathrm{z} \approx 200 \mathrm{~m}$ ).

\section{Conclusion}

In this study, we presented current results obtained for the ongoing inversion formulation directed to a more detailed reconstruction of the water velocity layer, constrained to the use of first arrivals traveltimes. The proposed scheme combines some underlying principles typically assumed in OAT, with parametrized velocity disturbances as exponetially decaying Fourier series, and straight ray assumption for traveltime evaluations in horizontally distributed OBN arrays. Results were found to provide more accurate reconstruction, then those obtained with homogeneous spatially-averaged velocity profile. Further development is directed towards improved spatial recovery, with additional complication regarding uncertainty in node positioning (joint inversion).

\section{Acknowledgements}

The authors are grateful to Carlos Eduardo Theodoro to provide the velocity profiles acquired in a real OBN acquisition campaign, and to Pedro Lins for some treatment in GLORYS reanalysis data. This research was supported by Petrobras through "Determinação da velocidade do som da coluna d'àgua utilizando dados de levantamentos sísmicos" project with Universidade Federal of Santa Catarina (UFSC), and ANP through the R\&D levy regulation, process: 2017/00071-6. 


\section{References}

BELO, W. C., 2011, A recirculação interna do giro subtropical do atlântico sul e a circulação oceânica na região do pólo pré-sal da bacia de santos: Diss. Universidade de São Paulo.

BERTRAND, A. and MACBETH, C., 2003, Seawater velocity variations and real-time reservoir monitoring: The Leading Edge, 22, 351-355.

BOEHM, G.; CRISE, A., and VESNAVER, A., 1995, Travel time inversion of marine seismic data for ocean sound speed reconstruction, in Full Field Inversion Methods in Ocean and Seismo-Acoustics, 291-296, Springer.

BREGMAN, N. D.; BAILEY, R. C., and CHAPMAN, C. H., 1989, Crosshole seismic tomography: Geophysics, 54, 200-215.

BUHMANN, M. D., 2003, Radial basis functions: theory and implementations, volume 12: Cambridge university press.

CORNUELLE, B.; WUNSCH, C.; BEHRINGER, D.; BIRDSALL, T.; BROWN, M.; HEINMILLER, R.; KNOX, R.; METZGER, K.; MUNK, W., and SPIESBERGER, J., 1985, Tomographic maps of the ocean mesoscale. part 1: Pure acoustics: Journal of physical oceanography, 15, 133-152.

COX, B. E. and VERSCHUUR, D. J., 2001, Tomographic inversion of focusing operators: 63rd EAGE Conference \& Exhibition, $\mathrm{cp}-15$.

CYPRIANO, L., 2019, Obn for pre-salt imaging and reservoir monitoring: Presented at the 16th International Congress of the Brazilian Geophysical Society, Rio de Janeiro.

DONDURUR, D., 2018, Acquisition and processing of marine seismic data: Elsevier.

ETTER, P. C., 2018, Underwater acoustic modeling and simulation: $C R C$ press.

GRAD, M.; MJELDE, R.; CZUBA, W.; GUTERCH, A., and SCHWEITZER, J., 2011, Modelling of seafloor multiples observed in obs data from the north atlantic-new seismic tool for oceanography?: Polish Polar Research, 375392.

JENSEN, F. B.; KUPERMAN, W. A.; PORTER, M. B., and SCHMIDT, H., 2011, Computational ocean acoustics: Springer Science \& Business Media.

LACOMBE, C.; SCHULTZEN, J.; BUTT, S., and LECERF, D., 2006, Correction for water velocity variations and tidal statics, in SEG Technical Program Expanded Abstracts 2006, 2881-2885, Society of Exploration Geophysicists.

LAJÚS, F. C. J. and KLEIN, A. H. F., 2021, The structure of water-layer sensitivity kernels in obntype acquisition geometries: Presented at the 17th International Congress of Brazilian Geophysical Society \& EXPOGEF, Rio de Janeiro, Brazil, 8-11 November 2021.

MUNK, W. and WUNSCH, C., 1979, Ocean acoustic tomography: A scheme for large scale monitoring: Deep Sea Research Part A. Oceanographic Research Papers, 26, 123-161.

SHERIFF, R. E., 2002, Encyclopedic dictionary of applied geophysics: Society of exploration geophysicists.

WOMBELL, R., 1996, Water velocity variations in 3d seismic processing, in SEG Technical Program Expanded Abstracts 1996, 1666-1669, Society of Exploration Geophysicists.

ZOU, Z.; ZHOU, H-W; GURROLA, H; BIAN, A; HUANG, Z, and ZHANG, J, 2018, Impact and solutions of seawater heterogeneity on wide-angle tomographic inversion of crustal velocities in deep marine environmentsnumerical studies: Journal of Earth Science, 29, 13801389. 